\title{
Construction of Structural Model for Strategic Foresighting and Public Policy
}

\author{
Fatma Ahmed Lari ${ }^{1,2}$, Darwish Ahmed Darwish Abdulla Lari ${ }^{1,3}$, Mohamed \\ Ahmed Darwish Abdulla Lari ${ }^{1,4}$
}

${ }^{1}$ Faculty of Technology Management and Business, Universiti Tun Hussein Onn Malaysia, 86400, Parit Raja, Batu Pahat, Darul Ta’zim, Johor, MALAYSIA

${ }^{2}$ Department of Municipalities and Transport (DMT), Al maamora, Abu Dhabi, UNITED ARAB EMIRATES

${ }^{3}$ Abu Dhabi Transmission \& Despatch Company, Abu Dhabi, UNITED ARAB EMIRATES

${ }^{4}$ Abu-Dhabi Police (GHQ ), Al morour, Abu Dhabi, UNITED ARAB EMIRATES

*Corresponding Author

DOI: https://doi.org/10.30880/ijscet.2020.11.02.020

Received 30 July 2020; Accepted 30 August 2020; Available online 02 September 2020

\begin{abstract}
This study was intended to establish a relationship between the strategic foresight dimensions with the public policy attributes of the United Arab Emirates (UAE) government. The data was collected through questionnaire survey staffs of UAE government organizations. A total of 397 valid responses were collected and analysed. The collected data was used to develop the relationship using AMOS software. It was found that the measurement model has fulfilled or achieved all the required criteria. For structural model evaluation, it found that the model has achieved all the set criteria of the evaluation. Results of the structural model evaluation found that strategic foresight influence $69 \%$ of the public policy making. It also found that the model has the significant relationship between strategic foresight dimensions and public policy. It was found that the model has $47 \%$ predictive relevancy. This result indicates that there is a substantial and direct effect between the strategic foresight and public policy. Hypothesis testing was conducted on the model and found that there is a significant relationship between strategic foresight dimensions and public policy is achieved. This indicates that the model can be applicable to UAE authority and contributes to the body of knowledge for further research.
\end{abstract}

Keywords: Strategic foresight, public policy, structural relationship model

\section{Introduction}

UAE's foresight focus began in 2015 at the government-corporate level. Foresight was sought by the UAE government as a strategy to exploit opportunities and counter potential challenges by building future models for health, educational, developmental and environmental sectors of the economy (MOCAF, 2018). Ministry of Cabinet Affairs and Future (MOCAF) is responsible for coordinating efforts of future initiatives, projects and policies (MOCAF, 2018). As evidence of achieving these futuristic visions, the government UAE announced at the World Government Summit that they could achieve and turn the vision of the future into a real-life success story, which can be defined as a Strategic Future Foresight that was built with international aspects. 
The framework for involving the ministry is to see through and making sure an effective implementation of the foresight trend in government goes through the plans. Additionally, the legislation, policies and programs will ensure the implementation of the future foresight between and among governmental organizations proceeds as planned (Al Hassan, 2017). The UAE's strategy for foresight is focused on human capital, smart technology, climate change, modern transportation, healthcare, sustainable development, political economy and security, these are considered as a megatrend based in foresight international reports. Foresight was promoted by the UAE government through building capacities and technical infrastructure nationwide as base infrastructure for the future foresight. The introduction of foresight in the educational curriculum and provision of scholarship (foreign and local) was one of the efforts put to ensure the promotion of foresight in the country enabling them to adopt this concept easily and in a wide range.

Based on what UAE's future strategy applies (Gossé et al., 2014) "State of the Future", foresight is one of the implementation mechanisms for establishing the strategy. As it cited "To enhance the future foresight in the organization as a daily work style", and the main tool to be used in the seven future priority sectors which are; Government \& Services, Education, Health, Sustainable Social Development, International Political Relations \& Security, Food \& Water Security, and Cyber Security. In the Government Excellence System guide, it was clear that the capabilities of future thinking are the top of concerns for the UAE government. This gives an indication that the UAE government considers the future foresight as a priority in all governmental processes in entities (Al Zaabi \& Awamleh, 2019). Strategic foresight and future-shaping would help the government to set up their lanes for the future and this will enable them to transform from being reactive to be more predictive in many fields such as public policy, which directly affects the economy and lifestyle wellbeing of these countries.

Presently, no study has cited in the literature on the relationship between strategic foresight and public policymaking especially related to the government entities organized by the Ministry of Cabinet Affairs and Future UAE as the case study. This research is, therefore, unique, as it will support to fill this gap. From the literature, it is evident that these relationships not been tested in the UAE government ministries. Therefore, given the relative importance of this sector to the economy of the UAE and other nations, it is time for a survey to be conducted in this industry to examine it and then build up the relationship.

\section{Conceptual model}

This study was to establish and assess a structural relationship model of strategic foresight and public policy using SEM AMOS software. The structural equation model based on the conceptual model as Fig 1. The model is divided into two parts: a measurement model and a structural model. The measurement model deals with the relationships between measured variables and latent variables. The structural model deals with the relationships between latent variables only to test the impact of cause-effect relationship.

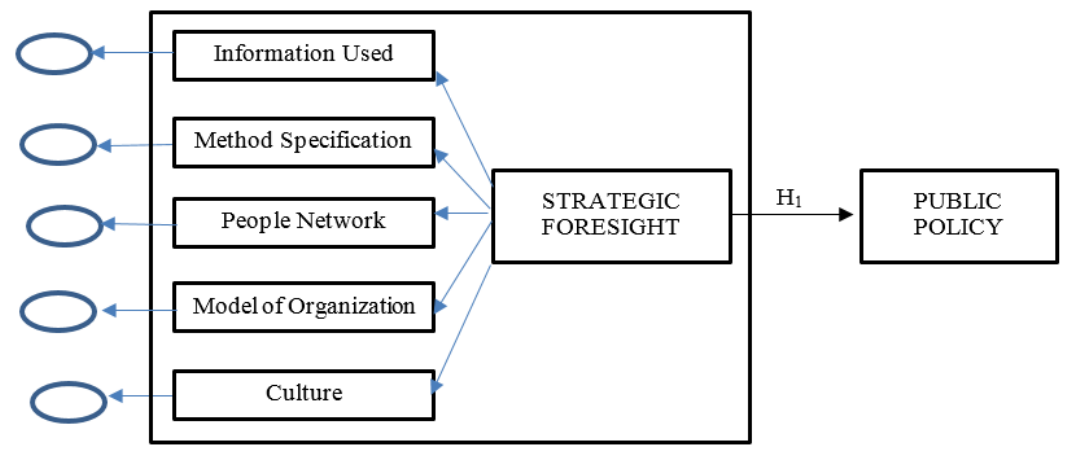

Fig 1 - Conceptual framework

At the measurement model level, there five models of strategic foresight dimensions and one model of the public policy. While at structural model level, the five models of the strategic foresight dimensions acts as exogenous constructs and the one public policy measurement model acts as endogenous construct

\section{Methodology}

The adopted a quantitative research approach where the data collected through questionnaire survey amongst the management staff of government organizations in the UAE. A total of 500 questionnaires were administered out of which $402(80.4 \%)$ were successfully retrieved. Among the retrieved questionnaires, 5 were found to be unusable due to either partial filling by the respondents or multiple answers on some questions. This brings the total usable questionnaires to 397 , which represent $79.4 \%$ of the total questionnaire originally administered. 
Based on respondents demography, about $54 \%$ of the respondents are male while the remaining $46 \%$ are female. Almost half of the respondents indicated that they are single while $42.8 \%$ are married. Less than $10 \%$ are divorcees. On the age of the respondents, exactly $10.3 \%$ are aged 20 years and below while $17.1 \%$ aged between 20 to 25 years. About $14 \%$ of the respondents fall within 26 to 30 years of age group. More than half of the respondents are aged between 31 years and 45 years while only $6.3 \%$ are aged above 45 years. The educational background of the respondents shows that about one-third hold diploma while $43.3 \%$ are bachelor degree holders. Exactly $15.4 \%$ of the respondents hold a master's degree while only $7.3 \%$ are Ph.D. holders. On the number of years of experience, slightly more than half of the respondents indicated that they have experience of 11 to 16 years. About a quarter of the respondents have experience of 5 to 10 years and $15.4 \%$ indicated that they have experience of fewer than 5 years. Less than $10 \%$ of the respondents indicated that they have experience of between 17 to 22 years.

\section{Measurement Model Assessment}

The assessment of measurement model is conducted through Confirmatory factor analysis (CFA) using AMOS-SEM software. It was conducted by adopting the recommended CB-SEM methodological process found in the multivariate texts (Hair, et al, 2010; Byrne, 2010; Kline, 2011). Assessment of the measurement model started by specifying each model which is model identification, parameter estimation, assessment of model's goodness-of-fit and lastly, respecification of the model. At each stage of the analysis, the validity of each construct was evaluated based on the established criteria for CB-SEM evaluation. Having established the validity and model fit of the individual constructs, it is necessary to assess the validity of the entire measurement model of the research prior to evaluating the structural model. The rationale for conducting this analysis was to establish the validity of the entire construct in harmony. The validity of the entire measurement model was assessed by examining the convergent validity and discriminant validity of the constructs in the model. Convergent validity is a measure of the degree to which the items or indicators of a construct are correlated with the construct. According to Hair et al., (2010) factor loadings that are statistically significant are indicators of convergent validity while indicators with a factor loading of .50 and above are regarded as sufficient to establish convergent validity. In CFA SEM analysis, the convergent validity of the construct assessed by the Bentler-Bonett coefficient (NFI). The recommended threshold for convergent validity using the NFI index is 90 (Hair et al., 2010; Kline, 2011; Byrne, 2010). In this research, the factor loading of all the items in the final measurement model and BentlerBonett coefficient (NFI) are used for the assessment of convergent validity (Hair et al., 2011). The results of the final measurement models' items as figure 2. It was found that NFI values were above 0.9 for all pulled constructs. The initial CFA model for all constructs in order to check the redundancy between the constructs together and to test the discriminant validity by checking the correlations among the constructs.

While discriminant validity measures the degree to which a construct is distinct from other constructs in the model. Hair et al. (2014) and Yeap et al., (2016) posited that discriminant validity measures the degree of uniqueness of a construct in relation to other constructs. Discriminant validity is achieved when the squared inter-construct correlations associated with a particular construct are greater than the corresponding inter-construct correlation estimates with other constructs (Hair et al., 2010). The decision rule for establishing discriminant validity is to ensure that the sum of squared correlations of indicators of a particular construct known as Average Variance Extracted (AVE) is greater than the correlation of the construct with any other construct in the model. The recommended threshold for AVE is .50 and above (Hair et al. 2014). Accordingly, discriminant validity of the model is assessed, so that the indicators should load more strongly on their own constructs than on other constructs in the model, and the average variance shared between the construct and its measures should be greater than the variance shared between each construct and other constructs (Fornell and Larcker 1981). It was found that all constructs exhibit sufficient of satisfactory discriminant validity (Fornell and Larcker 1981), where the square root of AVE (diagonal) is larger than the correlations (off-diagonal) for all reflective constructs 


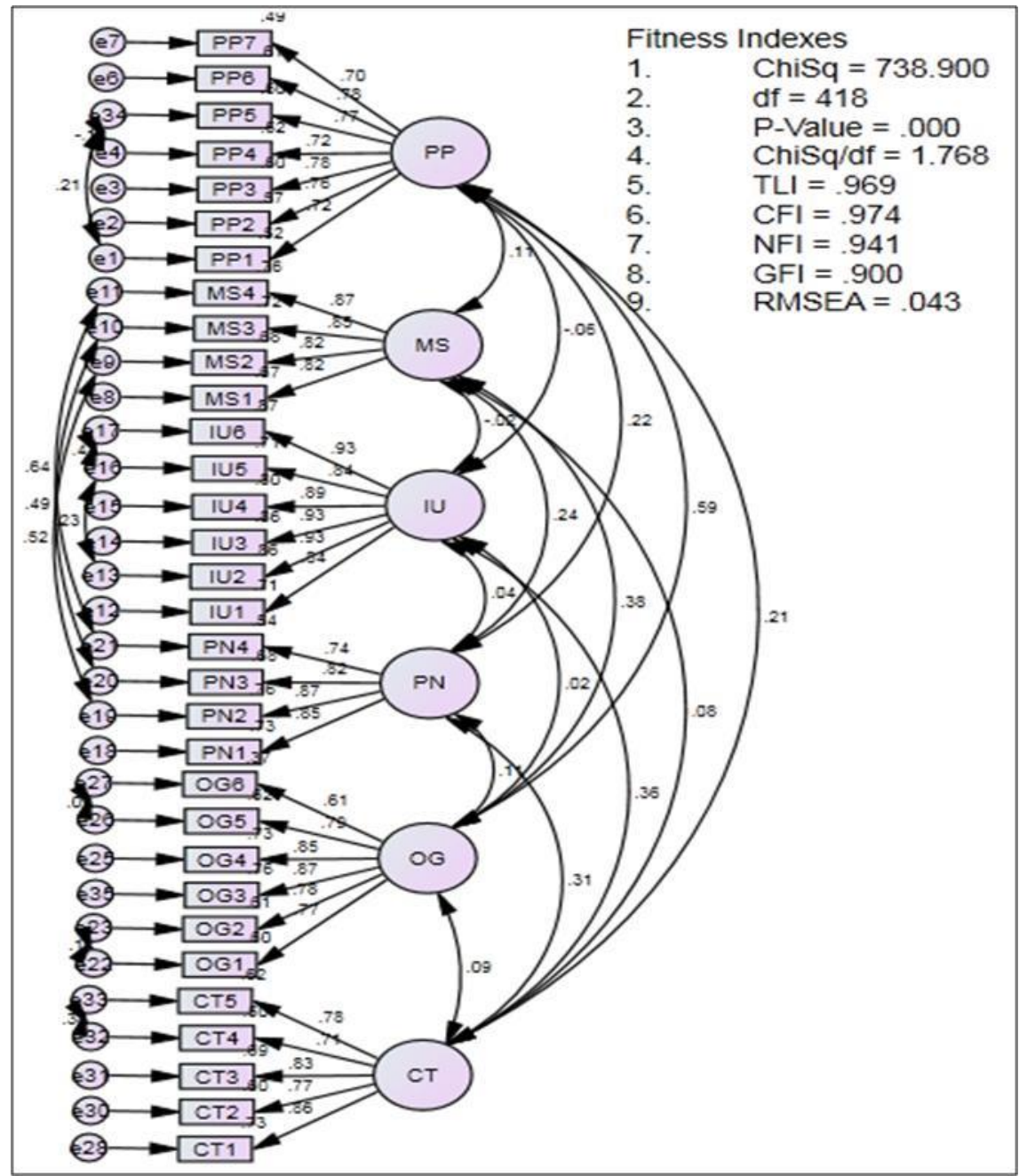

Fig 2 - Overall measurement model of constructs

\section{Structural Model Evaluation}

Upon satisfying the requirement for measurement model validity, the next stage in the SEM analysis involving the evaluation of the structural equation model in order to determine the causal relationship between the exogenous and the endogenous constructs. Using the AMOS graphics, the structural relationship between the constructs as the conceptual model was evaluated at the initial stage. It was found that the initial output of the structural model that most of fitness indices were achieved, however, some indices failed to meet the acceptable level. For example, all the observed factor loadings and their corresponding square multiple regressions met the required thresholds of 0.50 and 0.30 respectively. In respect of the fit indices, the NFI and p-value satisfied the criteria for acceptance while the CFI, RMSEA and other measures reported values below the acceptable thresholds. This suggests that model re-specification was required until the final structural model as figure 3. It was found that the final structural model satisfied with all the requirements for model acceptance. The standardized regression weights squared multiple regression, and all the goodness-of-fit indices meet the recommended thresholds. 


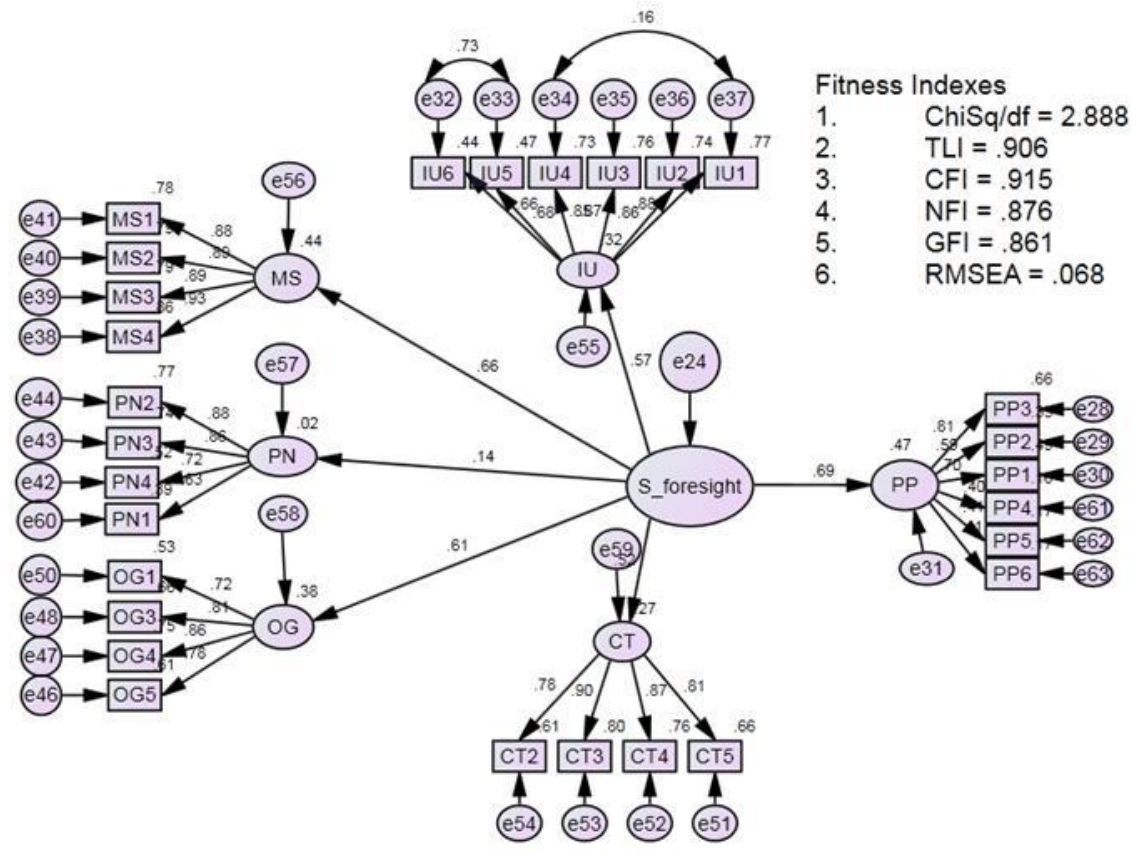

Fig 3 - Final structural model of the research constructs

The final structural model was arrived at after an iterative process of model re-specification. It shows the relationship between strategic foresight and its dimensions on one hand and the causal effect of strategic foresight and public policy. Table 1 shows the summary of the goodness-of-fit indices for both the initial and final structural models.

Table 1 - Goodness-of-fit for initial and final structural model

\begin{tabular}{|c|c|c|c|c|c|c|}
\hline Category & $\begin{array}{c}\text { Parsimonious } \\
\text { fit }\end{array}$ & $\begin{array}{c}\text { Absolute } \\
\text { fit }\end{array}$ & $\begin{array}{c}\text { Incremental } \\
\text { fit }\end{array}$ & $\begin{array}{c}\text { Incremental } \\
\text { fit }\end{array}$ & $\begin{array}{c}\text { Absolute } \\
\text { fit }\end{array}$ & Comment \\
\hline $\begin{array}{l}\text { Acceptance } \\
\text { Threshold }\end{array}$ & Chisq/df $\leq 3$ & $\mathrm{GFI} \geq .80$ & $\mathrm{CFI} \geq .90$ & $\mathrm{NFI} \geq .80$ & $\begin{array}{c}\text { RMSEA } \leq \\
.08\end{array}$ & - \\
\hline $\begin{array}{l}\text { Initial Structural } \\
\text { Model }\end{array}$ & 3.871 & 0.804 & 0.825 & 0.812 & 0.084 & Model not fit \\
\hline $\begin{array}{l}\text { Final Structural } \\
\text { Model }\end{array}$ & 2.888 & 0.861 & 0.915 & 0.876 & 0.068 & $\begin{array}{l}\text { Model fit and } \\
\text { accepted }\end{array}$ \\
\hline
\end{tabular}

Table 1 shows that at the initial model only two indices meet the desired thresholds; hence, there was the need for model re-specification. The initial structural model was then iteratively re-specified until all the fitness indices were within the acceptable limits. After the modifications, the final structural model was arrived at with all the fitness indices satisfying the required thresholds. From figure 3, the relationship between SF and PP, it indicates that the strength is 0.69 , which means Strategic Foresight (SF) influence 69\% of the Public Policy (PP) making. From the final model, it was found that the $\mathrm{R}^{2}$ value of the model is 0.47 which indicates that the model has $47 \%$ predictive relevancy. This result indicates that there is a substantial and direct effect between the strategic foresight and Public Policy. Hypothesis testing was conducted on the model and found that $\mathrm{P}$-value $=000[\mathrm{P} \leq 0.05$ for significant $]$ meaning there is a significant relationship between Strategic Foresight (SF) dimensions and Public Policy (PP) is achieved.

\section{Conclusion}

This paper presented a study on development and assessment of structural model using SEM-AMOS on the relationship between strategic foresight and public policy for the UAE. It was found that the measurement model has fulfilled or achieved all the required criteria. For structural model evaluation, it found that the model has achieved all the set criteria of the evaluation. Results of the structural model evaluation found that strategic foresight influence $69 \%$ of the public policy making. It also found that the model has the significant relationship between strategic foresight dimensions and public policy. It was found that the model has $47 \%$ predictive relevancy. This result indicates that there is a substantial and direct effect between the strategic foresight and public policy. Hypothesis testing was conducted on 
the model and found that there is a significant relationship between strategic foresight dimensions and public policy is achieved.

\section{Acknowledgement}

The authors would like to thank Universiti Tun Hussein Onn Malaysia, Abu Dhabi Transmission \& Despatch Company, Department of Municipalities and Transport (DMT), Al maamora and Abu-Dhabi Police (GHQ), Al morour, Abu Dhabi, United Arab Emirates.

\section{References}

AL HASSAN, M. K. (2017). Smart Safe Cities Technology Architecture to Assure Citizens' Happiness and Future Foresight to Achieve United Arab Emirates 100 Year Vision: Response Readiness, National Resilience and Future Accelerations (Doctoral dissertation, The British University in Dubai (BUiD)

Al Zaabi, F., \& Awamleh, R. (2019). Determinants of Soft Power: The Case of United Arab Emirates', Future Governments (Actions and Insights-Middle East North Africa, Volume 7)

Byrne, B. M. (2010). Structural equation modeling with AMOS: Basic concepts, applications, and programming (2nd ed.). New York: Routledge

Fornell, C., \& Larcker, D. F. (1981). Structural equation models with unobservable variables and measurement error: Algebra and statistics

Hair, J. F., Black, W. C., Babin, B. J., \& Anderson, R. E. (2010). Multivariate data analysis (7th ed.). NJ: Prentice Hall

Hair, J. F., Celsi, M., Money, A., Samouel, P., \& Page, M. (2011). Essentials of business research methods (2nd ed.). Armonk, NY: ME Sharpe

Hair, J. F., Hult, G. T. M., Ringle, C. M., \& Sarstedt, M. (2014). A primer on partial least squares structural equation modeling (PLS-SEM). Thousand Oaks: Sage

Hair, J. F., Sarstedt, M., Ringle, C. M. and Mena, J. A. (2012). An Assessment of the use of Partial Least Squares Structural Equation Modelling in Marketing Research. Journal of the Academy of Marketing Science. 40(3), pp. 414433

Kline, R. B. (2011). Principles and practice of structural equation modeling (3rd ed.). New York: The Guilford Press. Ministry of Cabinet Affairs and Future (MOCAF) (2018). Shaping the Future. Accessed 10/5/2019. https://www.mocaf.gov.ae/en/area-of-focus/future-foresight

Yeap, Z. X., Sim, K. S., \& Tso, C. P. (2016, November). Signal-to-noise ratio estimation technique for SEM image using linear regression. In 2016 International Conference on Robotics, Automation and Sciences (ICORAS) (pp. 1-5). IEEE 